\title{
IMPACTES DOS INCÊNDIOS FLORESTAIS EM ESCOMBREIRAS DE CARVÃO ABANDONADAS
}

\author{
Cármen Ferreira \\ Departamento de Geografia e CEGOT, \\ Faculdade de Letras da Universidade do Porto \\ dra.carmenferreira@gmail.com \\ Luciano Lourenço \\ Departamento de Geografia e CEGOT, \\ Faculdade de Letras da Universidade de Coimbra \\ luciano@uc.pt \\ Francisco Costa
}

Departamento de Geografia e CEGOT,

Instituto de Ciências Sociais da Universidade do Minho costafs@geografia.uminho.pt

Maria Gouveia

Aluna de Doutoramento, Departamento de Geografia e CEGOT

Faculdade de Letras da Universidade de Coimbra

mmalgouveia@gmail.pt

\section{RESUMO}

A indústria mineira tem apreciáveis impactes ambientais. No caso das minas de carvão, os resíduos resultantes da exploração - as escombreiras -, podem originar contaminação de solos, águas superficiais e aquíferos, constituindo um ponto importante de discussão na agenda política das questões ambientais. Após o abandono da atividade mineira, as escombreiras vão-se recobrindo de solo e de vegetação arbustiva e arbórea, que encobre os resíduos de carvão que as constituem.

Analisam-se e comparam-se as situações ocorridas nas escombreiras das minas de S. Pedro da Cova (Gondomar) e da mina da Bezerra (Porto de Mós), esta última integrada na área do Parque Natural das Serras de Aire e Candeeiros (PNSAC). Estas escombreiras foram encontradas em combustão lenta, após terem ocorrido incêndios florestais na área onde se localizam. Da combustão lenta das escórias de carvão resultou o abatimento das escombreiras, fumos, emissões de monóxido de carbono e anidridos sulfurosos e um cheiro intenso a enxofre que se dispersou pelas localidades em questão, provocando mal-estar na população. Referem-se as medidas de mitigação utilizadas na escombreira da Bezerra para acabar com a combustão lenta e diminuir os impactes ambientais dessa situação. Em contrapartida, nas escombreiras de S. Pedro da Cova, apesar dos documentos legais que impõem a adoção de medidas para superação do seu passivo ambiental, pouco ou nada se fez até agora.

Palavras-chave: Incêndios florestais; escombreiras de carvão; combustão lenta; degradação ambiental.

\section{Introdução}

Em Portugal os incêndios florestais têm sido recorrentes e destruído milhares de hectares de floresta. Os impactes dos incêndios florestais são diversos, destruindo de forma direta não só os povoamentos florestais, como também a biodiversidade, e provocam alteração na paisagem da área onde ocorrem. Foi sobretudo a partir da década de 70 do século passado, que se verificou um aumento crescente de área ardida, salientando-se, desde 1970 a 2014, o ano de 2003, com uma área ardida de 425726 ha responsável pela destruição de cerca de $8 \%$ da área de povoamentos florestais. Segundo o Instituto da Conservação da Natureza e Florestas (ICNF), no período pós 2003, o ano de 2014 é o terceiro melhor ano, em termos de área ardida desde 1 de Janeiro a 15 de Setembro, com apenas 11745 ha (ICNF, 2014). 
As minas de carvão desativadas localizam-se, sobretudo, em áreas de uso florestal daí que a ocorrência de incêndios nessas áreas também constituem um risco para as escombreiras que se encontram junto da área de mineração e que, por vezes, até se apresentam próximas de áreas edificadas. Ora, como as escombreiras abandonadas, são constituídas por acumulação de resíduos de carvão resultantes da exploração, constituem, por isso, material facilmente ignescente. A combustão lenta das escombreiras, que pode ocorrer durante largos períodos de tempo, provoca impactes ambientais diversos nas unidades territoriais onde se situam.

\section{A escombreira da mina de S. Vicente, em S. Pedro da Cova, Gondomar}

O concelho de Gondomar foi muito conhecido pela exploração das minas de carvão resultantes da bacia carbonífera do Douro que atravessa a parte oriental do concelho. As minas de S. Pedro da Cova, nas quais se insere a mina de S. Vicente, implantadas numa freguesia de cariz ainda rural, foram das mais importantes concessões mineiras dessa bacia carbonífera e uma das mais antigas minas de carvão exploradas em Portugal. (Ferreira, 2013).

A extração do carvão, na mina de S. Vicente, teve início em 1921 e encerrou em 1970. As rochas estéreis provenientes de atividade extrativa foram depositadas em montes que constituem as escombreiras, ou seja, locais de acumulação de resíduos de actividade extrativa, mas que hoje, terminada a mineração, são escombreiras abandonadas.

Os estéreis acumulados na escombreira da mina de $\mathrm{S}$. Vicente nunca sofreram qualquer tipo de tratamento ou manutenção e constituem um perigo potencial para a saúde pública e um risco para a população que ali vive.

Esta escombreira, à qual corresponde, atualmente, a cota de cerca de 150 metros, com uma altura de cerca de 50 metros, a partir da base, foi sendo, após do encerramento da atividade mineira em 1970, recoberta, naturalmente, por uma fina camada de solo que, posteriormente, permitiu o desenvolvimento de uma cobertura arbórea do tipo pinheiro bravo (Pinus pinaster) e eucalipto (Eucalyptus globulus), bem como de uma vegetação sub-arbustiva e herbácea diversas. As escórias de carvão foram, em parte, dissimuladas por essa delgada camada de solo onde se desenvolveu uma vegetação igual à das áreas envolventes.

Situada junto à vertente ocidental da Serra de $\mathrm{S}$. Justa, e revestida com espécies pirófitas, esta escombreira constituía e constitui uma área de risco de incêndio florestal. É precisamente através das encostas das serras que se propagam os incêndios dos concelhos vizinhos que vão afectar o concelho de Gondomar, e, neste caso, a freguesia de S. Pedro da Cova.

Um incêndio florestal ocorrido em 2003, afetou a área da escombreira da mina de S. Vicente que, depois de combatido, deu origem a uma combustão lenta no interior da escombreira que resiste até hoje. Os impactes ambientais dessa combustão lenta que dura há já 11 anos são diversos, do tipo físico, químico e biológico, produzindo-se, no solo, água e ar uma concentração de substâncias em quantidade, concentração e durante um período de tempo tal, que podem ameaçar a saúde das pessoas, e causam a perda da biodiversidade local.

A escombreira tem vindo a abater significativamente. A subsidência desta, resulta das características da distribuição de tensões no interior da escombreira que, devido à combustão, vai criando vazios para onde se deslocam os resíduos supra ou adjacentes (Rodrigues, 2001). A área de aparente coberto vegetal queimado vai aumentando sem ocorrência de incêndio superficial, o que significa que as raízes das espécies vão ardendo lentamente desde o interior da escombreira, o que configura um incêndio subterrâneo. A lenta combustão da escombreira vai consumindo as escórias (fig. 1), provocando a acumulação de enxofre à superfície do solo, 
bem como o aparecimento de lagoas de águas ácidas, por contaminação provocada pelas águas de escorrência (fig. 2).

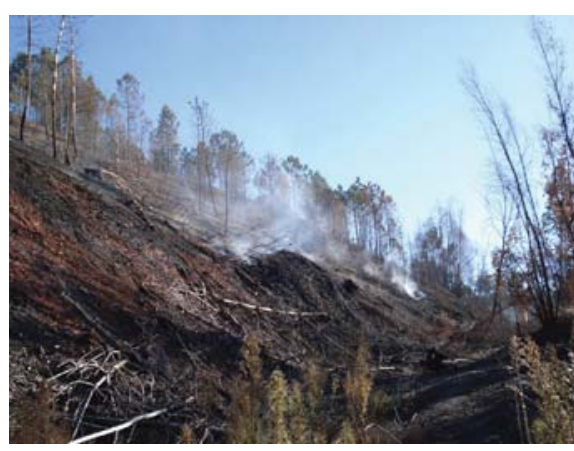

A

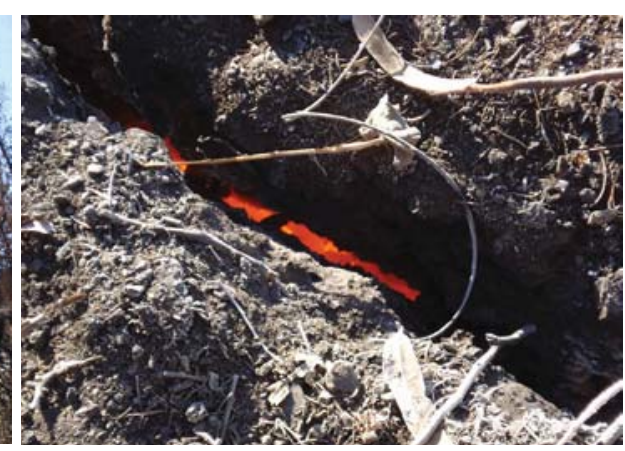

B

Figura 1 - A - Vista parcial da vertente da escombreira da mina de S. Vicente em combustão lenta; B - Fendas no solo que evidenciam a combustão interna da escombreira. (Fotografias de Cármen Ferreira, Out.2007).

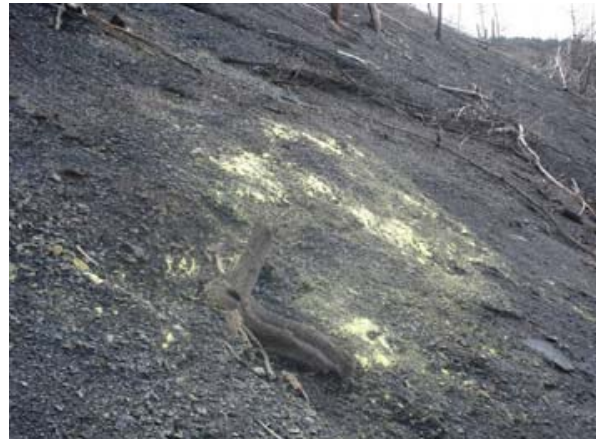

A escória; B - Lagoas de águas ácidas. (Fotografias de Cármen Ferreira, Março 2010).

A combustão lenta da escombreira acentua, necessariamente, os processos de erosão hídrica, os movimentos de vertente e a lixiviação dos resíduos minerais com a consequente formação de águas ácidas. O fumo eleva-se no ar vindo do interior do solo, onde as temperaturas da combustão atingem, pelo menos, $1000^{\circ} \mathrm{C}$ (J. Ribeiro et al., 2010). Como consequência, a temperatura superficial do solo é elevada e as fendas que se abrem no terreno são autênticos "fornos" que, atendendo à fragilidade do material, podem tornar o terreno movediço e consumir, literalmente, quem ou o que por lá passa. As fissuras e fendas abertas na escombreira proporcionam canais através dos quais o oxigénio pode circular e, assim, manter ativa a combustão.

Por estranho que possa parecer, durante estes 11 anos de combustão lenta na escombreira da Mina de S. Vicente, S. Pedro da Cova, nenhuma intervenção foi feita no local. Até aos dias de hoje, o problema da combustão lenta desta escombreira continua a existir e a constituir um 
risco para o complexo desportivo existente a umas dezenas de metros deste local, bem como para o edificado adjacente ao complexo desportivo.

\section{A escombreira da mina da Bezerra, em Serro Ventoso, Porto de Mós}

A mina da Bezerra fica situada na freguesia de Serro Ventoso, concelho de Porto de Mós, em plena área do Parque Natural das Serras de Aire e Candeeiros (PNSAC). Esta mina foi descoberta nos finais do século XIX ou início do século XX e encerrou, definitivamente, em 1959, quando o desinteresse pelo carvão da Sociedade Mineira do Lena conduziu à perda da concessão da Termoelétrica de Porto de Mós, em 1948, e, depois, à desativação da linha férrea, em 1959. As marcas da atividade mineira, se bem que esbatidas, são ainda perceptíveis no território, nomeadamente a escombreira, recoberta por carvalhos e medronheiros. 0 grande incêndio florestal que ocorreu em 2006 no lugar da Bezerra, incendiou a escombreira da antiga mina de carvão, que entrou em combustão lenta, ficando o fogo a lavrar no seu interior dando origem a fumos (figura 3) e cheiros intensos que provocam mal estar na população local.

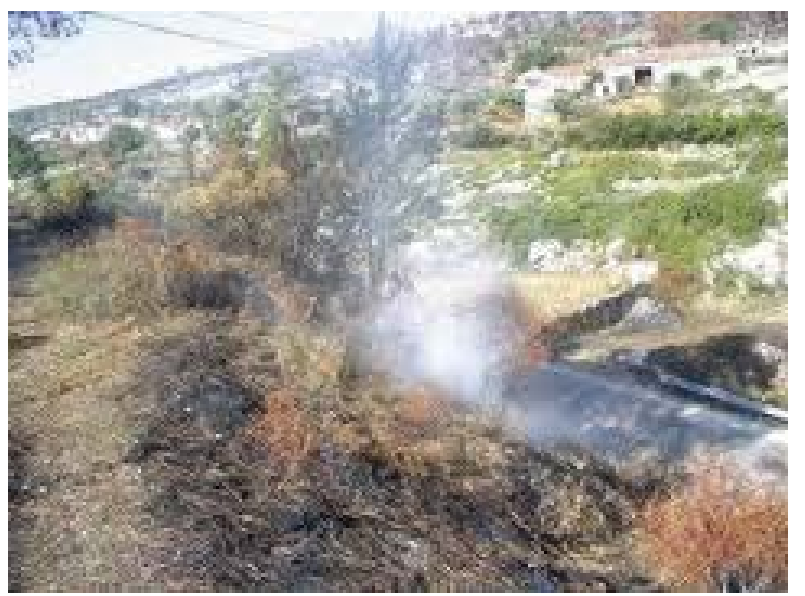

Figura 3 - Escombreira da mina da Bezerra em combustão lenta após o incêndio florestal que ocorreu no local em 2006.

Fonte:http://geopedrados.blogspot.pt/ 2006/09/o-incndio-no-pnsac.html

Tal como aconteceu na mina de S. Vicente, em S. Pedro da Cova, Gondomar, também nesta escombreira se pôde ver, desde o exterior, a chama da combustão interna da escombreira de que resultava a libertação de monóxido de carbono e de anidridos sulfurosos que, para além de tóxicos, são irritantes e incomodam a população.

Todavia neste caso, após a ocorrência do incêndio superficial, a autarquia de Porto de Mós procurou uma solução para resolver o problema do incêndio subterrâneo, a qual consistiu na asfixia da mina com terra, cortando o oxigénio para o seu interior. Embora sendo a escombreira de acesso difícil, tornando quase impossível a deslocação de máquinas para o local, o problema foi resolvido com a utilização de uma máquina giratória que assim permitiu a injeção de terra e a asfixia da combustão no interior da escombreira. Toda esta tarefa ficou terminada no final do ano de 2006 e o problema da combustão lenta da escombreira da mina da Bezerra deixou de existir. 


\section{Conclusão}

Os dois casos apresentados de escombreiras em combustão lenta tiveram resoluções diferenciadas por partes das autarquias locais responsáveis pela garantida da proteção civil de pessoas e do património natural. A consciencialização do risco que estas situações implicaram para as populações locais das unidades territoriais onde cada uma destas minas se insere, foi bem diferenciada em cada uma das autarquias. Com efeito, os agentes decisores do planeamento e ordenamento do território devem encontrar as medidas eficazes para cada situação de risco e que, nos casos em apreço, passam por devolver à comunidade, devidamente requalificados, esses locais que são exemplo de degradação ambiental, paisagística e humana.

\section{Bibliografia}

Ferreira, C. (2013) - "A degradação dos solos por atividade mineira: as minas de carvão de S. Pedro da Cova (Gondomar)”. Direito Rural, Vida Económica, Porto, p. 93-108.

ICNF (2014) - $7^{\circ}$ Relatório Provisório de Incêndios Florestais. http://www.icnf.pt/portal/florestas/dfci/ relat/

Ribeiro, J; Jesus, A. D. P.; Flores, D. (2010) - Petrografia e geoquímica orgânica das escombreiras de carvão da Bacia Carbonífera do Douro - implicações ambientais. Revista Electrónica de Ciências da Terra; http://e-terra.geopor.pt, ISSN 1645-0388, volume 9, n¹2.

Rodrigues, L. (2001) - “Instabilidade Geomorfológica em Explorações de Carvão Abandonadas, Área de Serro Ventoso-Bezerra, Concelho de Porto de Mós”. Actas do II Seminário Recursos Geológicos, Ambiente e Ordenamento do Território, Vila Real, p. 145-154. 